\title{
PEMANFAATAN VIDEO DAN ANIMASI DENGAN KARAKTER HELA PADA PANDANGAN UMUM TERHADAP ANAK PENGIDAP AUTISTIK
}

\author{
Andi Tejawati', Hanif Aulia'2, Muhammad Bambang Firdaus ${ }^{3}$, \\ Fadli suandi' ${ }^{4}$, lathifah ${ }^{5}$, M. Khairul Anam ${ }^{6}$ \\ Universitas Mulawarman, Samarinda 1,2,3 \\ Politeknik Negeri Batam, Batam ${ }^{4}$ \\ Universitas Teknokrat Indonesia 5 \\ STMIK Amik Riau, Pekanbaru 6 \\ Barong Tongkok Kampus Gn.Kelua Universitas Mulawarman 1,2,3 \\ Jl. Ahmad yani, Batam Kota, Kepulauan Riau ${ }^{4}$ \\ Jl. ZA. Pagar Alam, Kota Bandar Lampung ${ }^{5}$ \\ Jl. Purwodadi Indah, Km 10 Panam, Pekanbaru ${ }^{6}$ \\ 1 anditejawati117@yahoo.com, ${ }^{2}$ cinema.hanifaulia@gmail.com, ${ }^{3}$ bambangf@fkti.unmul.ac.id \\ ${ }^{4}$ fadli.suandi@polibatam.ac.id, ${ }^{5}$ lathifah@teknokrat.ac.id, ${ }^{6}$ khairulanam@sar.ac.id
}

\begin{abstract}
Video is one form of entertainment that we often encounter everyday, in addition to being entertainment, video can also be a medium for education, besides there are types of videos, one of which is animation, the merging between video and animation is a combination as an educational media. From time to time, children with autism always increase, adding that this autistic person does not compare well with the public's knowledge about autism, this causes autistic people isolated from the environment, and also autistic people who need bullying assistance. Therefore, the combination of video and animation is expected to be a supported medium between people with autism and the general public, to convey what they want as autistic people, to be accepted in society, and to socialize like a normal human being. This video will feature interviews from various sources such as therapists, parents of children with autism, and the community, this video will also display animations to add information about autism, this animation will be displayed for each character chosen Hela, Hela for fictional characters made using the cheated technique using the Duik Tool which is an animation making technique with bone structure to move it
\end{abstract}

Keywords: Autism, Video, Animation, Rigged Animation, Duik Tool.

\begin{abstract}
Abstrak
Video adalah salah satu bentuk hiburan yang sering kita jumpai sehari-hari, selain sebagai hiburan, video juga dapat menjadi media untuk edukasi, selain ada banyak jenis video, salah satunya adalah animasi, penggabungan antara video dan animasi ini menajadi satu kombinasi sebagai media edukasi. Dari masa ke masa, anak pengidap autis selalu bertambah, sayangnya pertambahan pengidap autis ini tidak berbading baik dengan pengetahuan masyarakat mengenai autis, hal ini menyebabkan para pengidap autis seringkali terkucilkan dari lingkungan, dan tak jarang juga para pengidap autis mengalami kasus bullying. Maka dari itu, kombinasi video dan animasi ini diharapkan dapat menjadi media perantara antara pengidap autis dan masyarakat umum, untuk menyampaikan apa yang mereka inginkan sebagai pengidap autis, yaitu keinginan untuk diterima di masyarkat, dan bersosialisasi layaknya manusia normal. Video ini akan menampilkan wawancara dari berbagai narasumber seperti terapis, orang tua dari pengidap anak autis, dan masyarakat, video ini juga akan nemampilkan animasi untuk nenambahkan informasi mengenai autis, animasi ini akan dikemas dalam bentuk sebuah karakter bernama Hela, Hela adalah karakter fiktif yang dibuat dengan menggunakan Teknik rigged menggunakan Duik Tool yaitu teknik pembuatan animasi dengan pemberian struktur tulang untuk menggerakannya
\end{abstract}

Kata kunci : Autis, Video, Animasi, Animasi Rigged, Duik Tool. 


\section{Pendahuluan}

Menurut WHO (World Health Organization), ASD (Autistism Spectrum Disorder) mengacu pada berbagai kondisi yang dicirikan oleh beberapa tingkat perilaku sosial, komunikasi dan bahasa yang terganggu, dan rentang minat dan aktivitas yang sempit yang unik bagi individu yang dilakukan berulang-ulang. ASD dimulai pada masa kanak-kanak dan cenderung bertahan hingga remaja sampai dewasa. Dalam banyak kasus, kondisi ini terlihat selama 5 tahun pertama kehidupan. Individu dengan ASD sering memperlihatkan kondisi lain yang terjadi, termasuk epilepsi, depresi, kecemasan dan gangguan attention deficit hyperactivity (ADHD). Tingkat fungsi intelektual pada individu dengan ASD sangat bervariasi, membentang dari penurunan yang sangat besar ke tingkat yang lebih tinggi.

Di Indonesia, khususnya Samarinda sendiri, anak berkebutuhan khusus, khususnya pengidap autistik sering kali menerima perlakuan berbeda dari anak yang normal, tak jarang anak autistik ditolak disekolah umum karna perbedaannya dengan anak normal pada umumnya, maka dari itu saya membuat penelitian berbentuk kombinasi video dan animasi ini [1], untuk memperlihatkan kepada masyarakat tentang anak berkebutuhan khusus pengidap autistik, dan bagaimana persepsi umum terhadap anak autistik, agar masyarakat dapat lebih memahami kebutuhan mereka, dan dapat mengerti cara memperlakukan mereka, dan para pengidap autistik dapat beraktifitas dengan bebas tanpa rasa terkucilkan, atau terasingkan di lingkungan masyarakat umum.

Video adalah salah satu bentuk hiburan yang paling mudah kita jumpai sehari - hari, namun selain menjadi media hiburan, video juga dapat menjadi media kampanye, selain video, video yang dikombinasikan dengan animasi juga tentunya lebih mudah diterima oleh segala rentang umur, penulis membuat video yang dikombinasikan agar dapat dinikmati oleh semua umur [2].

Penelitian ini yang dilaksanakan di klinik Liliput Samarinda, sebagai media kampanye mengenai anak autis, untuk disebarkan kepada masyarakat luas agar lebih teredukasi mengenai apa itu autis, apa yang mereka butuhkan, bagaimana cara memperlakukan mereka dengan benar, dan bagaimana cara mempublikasikan kapanye berbentuk video ini agar dapat ditonton oleh masyarakat umum.

\section{Tinjauan Pustaka dan Teori 2.1 Metode Penelitian}

Rigging adalah metode menggerakan animasi karakter dengan pemberian tulangtulang dan struktur yang kompleks sehingga membuat animasi bergerak sesuai dengan sruktur tubuh yang nyata. Rigging merupakan suatu proses untuk menyisipkan tulang ke model manusia, sendi-sendi dari tulang harus diletakan di posisi yang sesuai pada model manusia yang dibuat untuk memetakan kerakter sesuai dengan posisi geraknya [3].

\subsection{Multimedia}

Istilah Multimedia berasal dari kata multi berarti banyak atau bermacam-macam dan kata media yang berarti sarana yang dipakai untuk menyampaikan sesuatu atau alat untuk mendistribusikan dan mempresentasikan informasi [4]. Multimedia dapat diartikan sebagai penggunaan beberapa media yang berbeda untuk menggabungkan dan menyampaikan informasi dalam bentuk teks, audio, grafik, animasi dan video[5].

\subsection{Video}

Video adalah sistem gambar hidup atau gambar bergerak yang saling berurutan. Terdapat dua macam video yaitu video analog dan video digital. Video analog dibentuk dari deretan sinyal elektrik (gelombang analog) yang direkam oleh kamera dan dipancarluaskan melalui gelombang udara. Sedangkan videi digital dibentuk dari sederetan sinyal digital yang berbentuk, yang menggambarkan titik sebagai rangkaian nilai minimum atau maksimum, nilai minimum brarti 0 dan nilai maksimum berarti 1 [6].

\subsection{Animasi}

Kata animasi berasal dari Bahasa Yunani kuno, yaotu animo yang berarti hasrat, keinginan atau minat. Lebih dalam lagi mempunyai makna roh, jiwa atau hidup. Pada masyarakat kuno, animism adalah suatu kepercayaan bahwa semua benda mempunyai jiwa (hidup).

Animasi pada dasarnya adalah suatu disiplin ilmu yang memadukan unsur seni dengan teknologi. Sebagai disiplin ilmu seni ia terikat dengan aturan atau hukum dan dalil yang mendasari keilmuan itu sendiri, yaitu prinsip animasi [7]. Sedang teknologi untuk menunjang keilmuan itu sendiri adalah perangkat yang dapat merekam bauh seni animasi tersebut[8]. Seperti kamera fil, atau video, perekamsuara, perangkat 
lunak computer, serta sumber daya manusia. Semuanya bersinergi hingga terwujudlah sebuah karya animasi [7].

Dapat dikatakan animasi merupakan suatu media yang tercipta dari 2 media disiplin yaitu film dan gambar, untuk mengerti dan menciptakan animasi harus mengerti dan memahami dua media tersebut.

\subsection{Duik Tool}

Duik tool adalah plug-in yang digunakan pada Adobe After Effect. Duik tool adalah alat untuk membuat animasi rigging, Duik menggunakan metode reverse kinematics rigging. Duik tool sangat mudah untuk dikontrol, tetapi sulit untuk mendapatkan gerakan yang lembut dan elastis pada animasi [9].

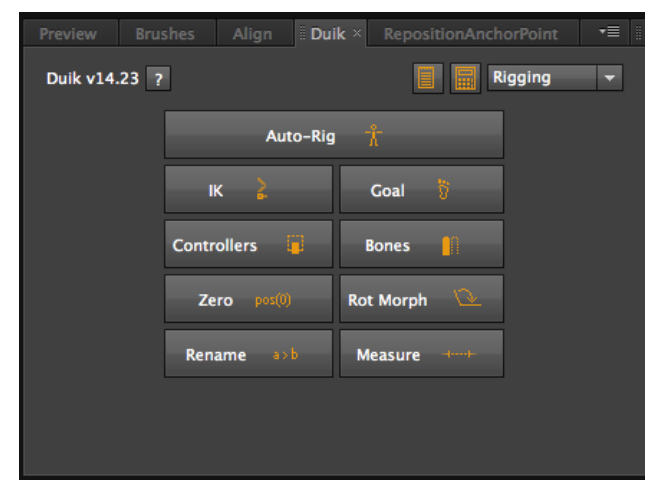

Gambar 1. Tampilan Duik Tool

Rigging adalah pemberian tulang (bone) pada objek yang akan dibuat animasi. Duik menyediakan tools utama rigging, yang biasa ditemukan di perangkat lunak 3D seperti IK (inverse kinetic), controller, dan bones dengan menyesuaikannya untuk animasi 2D di After Effect. Dengan menggunakan Duik, user dapat membuat rig karakter kompleks dan menggunakan teknik animasi canggih yang biasanya digunakan di perangkat lunak 3D [10].

\subsection{Adobe Premiere Pro}

Adobe premiere pro adalah software editing video, audio, maupun text untuk menggabungkan beberapa footage video, dan memadukannya dengan lagu, dan juga text. Penulis menggunakan software Adobe Premiere Pro untuk menyatukan timeline video dari beberapa footage yang sudah di ambil, dan menggabungkannya dengan backsound, dan memberikan teks, juga termasuk proses pewarnaan gambar dan lainnya[11].

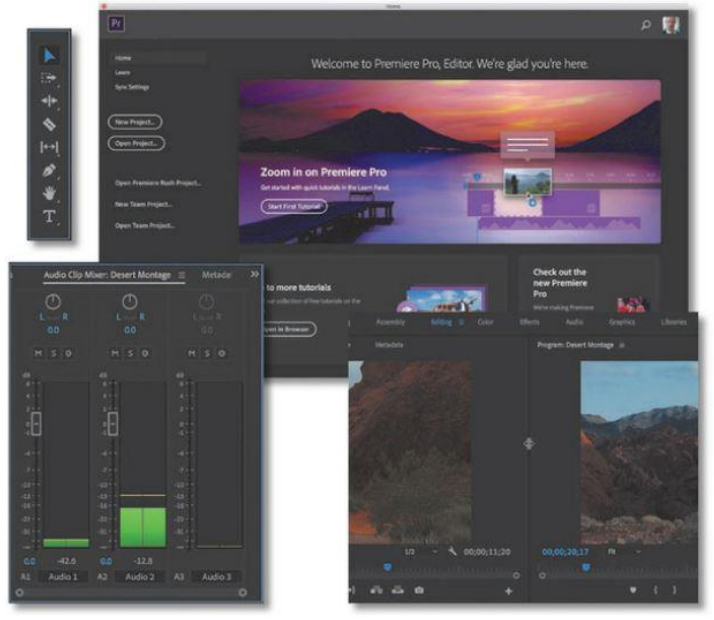

Gambar 2. Tampilan Adobe Premiere Pro

\subsection{Adobe After Effect}

Adobe After Effect adalah software untuk pengolahan visual effect, adobe after effect dapat digunakan untuk membuat animasi teks, animasi bumper, dan menambahkan visual effect pada video. Penulis menggunakan Adobe After Effect untuk membuat animasi, membuat lower third tittle, dan beberapa efek animasi pada video yang akan dibuat[11].

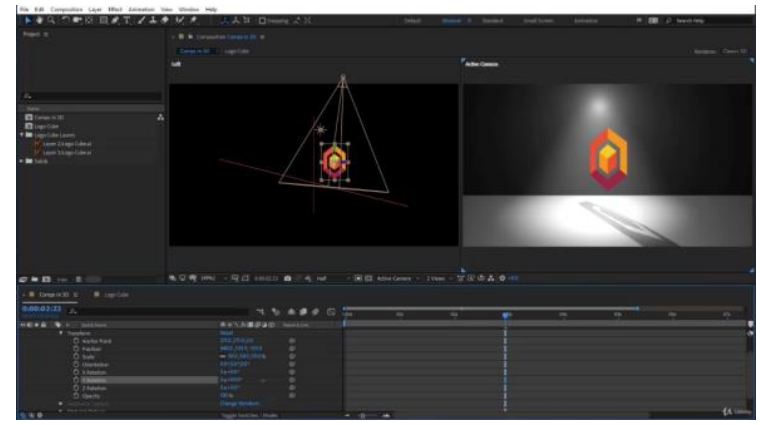

Gambar 3. Tampilan Adobe After Effect

\subsection{Adobe Audition}

Adobe Audition adalah software pengolahan suara, Adobe Audition dapat digunakan sebagai multitrack audio digital recording, Adobe Audition dapat melakukan perekaman suara, memperbaiki kualitas suara, dan juga menambahkan efek suara, penulis menggunakan Adobe Audition untuk melakukan perekaman, memperbaiki kualitas audio, dan mixing backsound music. 


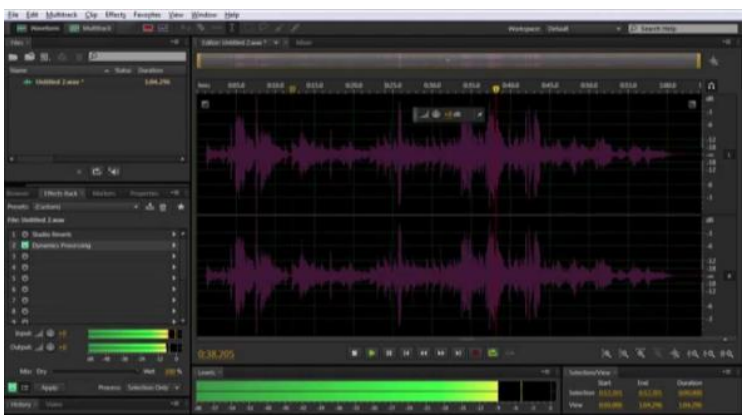

Gambar 4. Tampilan Adobe Audition

\subsection{ASD (Austin Spectrum Disorder)}

ASD atau bias juga disebut autistik merupakan suatu gangguan perkembangan pervasif. Banyak diantara individu autistik mempunyai gangguan perkembangan dalam motorik kasarnya. Kadang-kadang tonus ototnya lembek sehingga jalannya kurang kuat. Keseimbangan tubuhnya kurang bagus. Fisioterapi dan terapi integrasi sensoris akan sangat banyak menolong untuk menguatkan ototototnya dan memperbaiki keseimbangan tubuhnya.

Delapan puluh persen anak autistik memiliki IQ di bawah 70 (Davison, 1998) yang bisa digolongkan juga sebagai retardasi mental. Akan tetapi autistik berbeda dengan retardasi mental. Penderita retardasi mental menunjukkan hasil yang memprihatinkan pada semua bagian dari sebuah tes inteligensi. Berbeda dengan penderita autistik, mereka mungkin menunjukkan hasil yang buruk pada hal yang berhubungan dengan bahasa dan logika tetapi mereka ada yang menunjukkan hasil yang baik pada kemampuan visual-spatial, perkalian empat digit, atau memiliki long-term memori yang baik.

\section{Metode Penelitian}

\subsection{Waktu dan tempat penelitian}

Penelitian ini dilaksanakan pada bulan Februari - April 2019, dan adapun tempat penelitian ini dilaksanakan di yayasan Kasih dan Cahaya kehidupan, klinik liliput samarinda yang berlokasi di Alamat Jl. Ade Irma Suryani no 3A.

\subsection{Kerangka Penelitian}

Kerangka kerja yang digunakan dalam penelitian ini adalah berdasarkan diagram alir (Flowchart) dalam pembuatan video dan animasi ini adalah sebagai berikut.

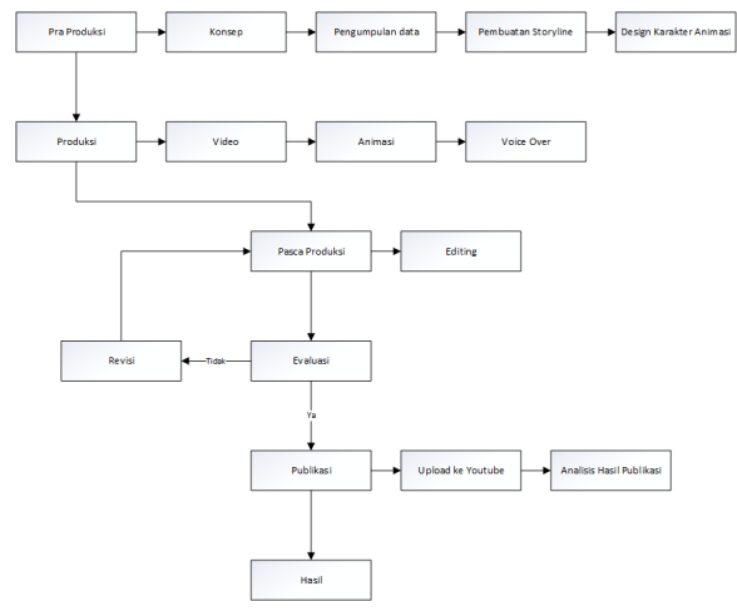

Gambar 5. Flowchart pembuatan animasi \& video

\subsection{Metode Pengumpulan Data}

Teknik pengumpulan data yang digunakan oleh penulis dalampenelitian ini adalah dengan Teknik Wawancara, Observasi, dan Studi literatur.

Metode wawancara dilakukan langsung dengan pihak yang bersangkutan. Dalam hal ini, akan dilakukan wawancara langsung dengan ahli psikologis khusus anak berkebutuhan khusus, pengajar di klinik liliput samarinda, dan juga orang tua dari anak yang mengidap autistik mengenai permasalahan - permasalahan yang sering dihadapi oleh anak autistik, apa yang dibutuhkan oleh anak autistik, dan bagaimana cara menghadapi anak autistik tanpa mendiskriminasikan atau membeda-bedakan anak autistik dengan anak normal. Sesi wawancara ini akan direkam untuk dijadikan footage dalam produk akhir video.

Metode observasi digunakan untuk mengamati rutinitas keseharian anak autistik yang dijadikan objek penelitian, dalam hal ini peneliti akan mengikuti rutinitas satu orang anak autistik, dan akan melakukan pengamatan mendalam kepada anak tersebut, informasi yang didapatkan anak dicatat dan juga direkam untuk footage produk akhir video.

Studi Literatur dalam penelitian ini, dilakukan pengumpulan data dan mempelajari berbagai sumber referensi seperti buku, dan hasil - hasil penelitian mahasiswa dalam bentuk skripsi, serta mencari referensi dari internet yang berkaitan dengan permasalahan yang sedang diteliti. 


\subsection{Alat dan Bahan Penelitian}

Dalam pembuatan kombinasi video dan animasi ini, dibutuhkan alat dan bahan yang merupakan gabungan dari software dan hardware, adapun alat dan bahan yang digunakan untuk membuat kombinasi video dan animasi adalah sebagai berikut :

Perangkat Lunak (software) yang digunakan oleh penulis untuk melakukan penelitian ini adalah sebagai berikut:
1) Adobe premiere Pro CC 2015
2) Adobe After Effect CC 2015
3) Adobe Audition CC 2015
4) Adobe Photoshop CC 2015
5) Adobe Lightroom Clasic CC
6) Adobe Illustrator

Kebutuhan Perangkat Keras (Hardware) yang digunakan oleh penulis untuk melakukan penelitian ini adalah sebagai berikut:

1) Kamera Nikon D7200

2) Lensa Nikon af-s 35MM f/1.8

3) Lensa Nikon af-s 50MM f/1.8G

4) Lensa Tamron 17-50 f/2.8 for Nikon

5) Lavalier Mic Booyaa

6) Shotgun Mic Takstar

7) Lighting Godox SK300II

8) Led Panel YN-300II

9) Macbook Pro MD101

10) Komputer editing (Intel Core i5, 8gb RAM, NVDIA GTX 750 TI)

\subsection{Tahapan pra produksi}

Pra produksi merupakan tahap perencanaan dan persiapan dalam pembuatan video. Dalam penelitian ini, dapat dijabarkan tahapan pra produksinya adalah sebagai berikut.

Tema video dan animasi ini adalah mengenai keresahan orang tua yang memiliki anak berkebutuhan khusus terutama penyandang autistik. Orang tua yang takut akan masyarakat yang salah menilai anaknya dan salah memperlakukan anaknya, dan peranan masyarakat untuk pertumbuhan anak berkubutuhan khusus penyandang autistik.

Sinopsis Anak berkebutuhan khusus penyandang autistik adalah anak yang terlahir tidak normal, anak autistik sangat sensitif sehingga ia mungkin akan sangat terganggu, bahkan tersakiti oleh suara, sentuhan, bau, atau pemandangan yang tampak normal bagi orang lain. Anak berkebutuhan khusus sering kali merasa terganggu dengan orang disekitarnya, hal ini kadang membuat masyarakat memandang sebelah mata anak pengidap autistik, video dokumenter ini menceritakan mengenai anak pengidap autistik dari berbagai macam persepsi, termasuk dari para ahli, dari berbagai kalangan masyarakat, dan juga dari orangtua anak penyandang autistik, dan juga cara memperlakukan anak autistik sebagaimana mestinya untuk membantu perkembangannya.

Riset pustaka atau literature dengan cara mengumpulkan informasi dari internet, tenaga ahli dan juga terapis dari klinik liliput samarinda, dan juga orang tua anak berkebutuhan khusus. Kemudian informasi di olah menjadi naskah, dan juga dilakukan beberapa wawancara dengan beberapa narasumber. Peneliti juga melakukan riset untuk tempat pengambilan gambar, dan juga melakukan observasi kegiatan objek penelitian yaitu anak penyandang autistik untuk didokumentasikan sebagai footage video. Pemilihan lokasi wawancara juga dilakukan dengan seksama agar mendapatkan hasil sesuai dengan rencana

Penelitian ini melakukan observasi secara langsung melihat keadaan anak berkebutuhan khusus penyandang autistikm, saya mengamati tingkah laku kesehariannya dalam bersosialisasi, baik itu di sekolah, ataupun ditempat terapi, pada saat melakukan observasi, akan di abadikan dalam video documenter, yang akan menjadi produk yang akan saya buat nantinya.

Selain observasi, saya juga melakukan wawancara kepada beberapa orang, antara lain ahli psikologis anak, masyarakat umum, dan juga orang tua anak. Wawancara juga akan didokumentasikan dalam video, yang nantinya akan dimasukan kedalam produk yang saya buat. Wawancara kepada ahli psikologis lebih ditekankan kepada bagaimana penerapan ilmuilmu psikologis dalam menangani anak berkebutuhan khusus penyandang autistik, sifatsifat anak autistik dalam pandangan medis, dan menjelaskan mengenai anak berkebutuhan khusus secara singkat.

Untuk wawancara dengan orang tua membahas tentang kebiasaan anak sehari-hari, kekhawatiran orang tua tentang kondisi anak, kan harapan orang tua tentang perlakuan masyarakat terhadap anak autistik.

Sedangkan untuk wawancara dengan masyarakat lebih ditekankan kepada persepsi masyarakt 
umum tentang anak berkebutuhan khusus penyandang autistik, keresahan masyarakat, dan harapan masyarakat. Untuk masyarakat sendiri akan di ambil dari berbagai latar belakang, yang akan dilakukan kepada 3-4 orang dengan profesi yang berbeda-beda.

Dalam video terdapat animasi yang disematkan Karakter Hela, animasi berupa karakter kartun bernama Hela, Hela adalah tokoh fiksi yang peduli dengan anak autistik, yang memberikan penjelasan mengenai autistikm. Hela di desain menyerupai pil kapsul yang mempunyai tangan, kaki. Pengisi suara Hela adalah wanita berumur 20-30 tahun, karakter hela adalah ramah, periang.

Animasi dipakai dalam bentuk animasi explainer 2 dimensi, dimana animasi dipakai untuk menjelaskan mengenai penjelasanpenjelasan yang akan disampaikan dalam video, animasi menggunakan tokoh karakter yang diberi nama Hela, Hela berperan sebagai narator, dimana hela akan membacakan narasi, dan juga menjelaskan mengenai sindrom autistik, dan juga memberi kesimpulan mengenai keseluruhan video. Nantinya animasi akan mempunyai porsi kurang lebih $40 \%$ dari keseluruhan video.

Desain Video diperoeh dalam bentuk dokumenter, sebagian besar video di ambil pada saat observasi, video di ambil menggunakan 1 kamera pada saat observasi. Pada saat melakukan wawancara, set akan di atur dengan 3 titik pencahayaan, yaitu menggunakan key light, fill light dan back light.

Setting lighting ini akan menghasilkan the Rembrandt triangle, yaitu bayangan segitiga di sekitar pipi, yang akan menampilkan sisi dramatis, dan mood yang terlihat lebih gelap pada saat wawancara, akan menampilkan sisi lebih kuat didalam framing, sedangkan back light akan menampilkan dimensi yang lebih dalam membuat fokus lebih baik pada karakter yang akan di wawancara.

Desain Audio menggunakan shotgun mic yang diletakan di atas kamera, untuk mengangkap suara yang lebih jernih, dan lebih fokus, sehingga dapat menghindari ambience suara disekitar.

Sedangkan pada saat wawancara, digunakan 2 titik microphone, titik pertama menggunakan lavelier (clip-on) yang diletakan di pakaian narasumber, untuk menghasilkan suara dari narasumber yang lebih jernih dan bulat, di titik kedua, akan menggunakan shotgun mic yang diletakan di atas narasumber dan mengarah kebawah, untuk mengambil dimensi suara dalam ruangan, sehingga dimensi suara terlihat lebih nyata, pada proses editing, porsi titik suara dengan lavelier akan terdengar porsi lebih besar, sedangkan porsi suara dengan shotgun mic terdengar lebih sedikit.

Setelah video selesai dibuat, video akan dipublikasikan di youtube, dan akan dibagikan ke berbagai sosial media seperi Instagram, dan akan menggunakan fitur Promote instagram. untuk proses analisis, video akan pantau selama 6 hari, proses analisis akan mendapatkan hasil apakah video tersebut dapat disebarluaskan secara baik di masyarakat, dan diliat apakah video tersebut mendapatkan respon positif atau negative di masyarakat di masyarakat umum.

Analisis publikasi video akan didapatkan jumlah viewer video yang sudah di promosikan, dan akan dinilai apakah promosi tersebut berhasil dalam meningkatkan jumlah viewer. Analisis dilakukan selama 6 hari, penilaian hasil video tersebut di ukur dari tingkat keberhasilan promosi terhadap video.

\section{Hasil Dan Pembahasan}

\subsection{Shoot TimeLine}

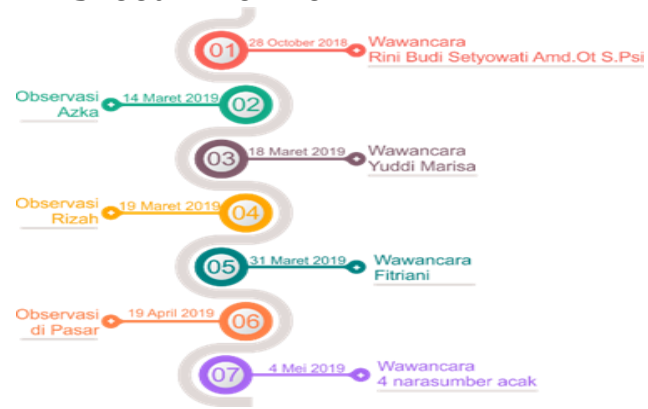

Gambar 6. Shoot Timeline

proses pengambilan gambar dilaksakan mulai tanggal dilaksanakan mulai tanggal 28 Oktober 2018 sampai dengan 4 Mei 2019, pada proses pengambilan gambar dapat dijabarkan sebagai berikut:

\section{a. Wawancara}

Pada proses wawancara, penulis membagi 2 tipe wawancara, yang pertama adalah In-Depth Interview atau wawancara mendalam, yaitu penulis telah mempersiapkan terlebih dahulu pertanyaannya dan diberikan oleh narasumber, 
agar narasumber dapat mempersiapkan jawaban waancara dengan baik, tipe yang kedua berupa rapid question, dimana pada wawancara ini penulis mencari narasumber secara random, dan melakukan interview dengan menanyakan pertanyaan yang belum diketahui sebelumnya oleh narasumber, hal ini dilakukan untuk mendapatkan respon natural dari narasumber, penulis ingin mengetahui sejauh mana pengetahuan narasumber tanpa narasumber mempersiapkan jawaban terlebih dahulu.

Pada tipe wawancara In-Depth Interview penulis melakukan wawancara kepada 3 orang yaitu dengan ibu rini ibu Rini Setyowati Amd.Ot S.Psi selaku terapis okupasi, bapak Yudi marissa selaku orang tua dari Rizah anak pengidap autis dan ibu Fitriani selaku orang tua dari Azka anak pengidap autistik.

Sedangkan tipe wawancara Rapid Question dilakukan oleh 4 narasumber random yang ditemui penulis.

b. Observasi

Penulis melakukan pengambilan gambar dengan malakukan obseravsi, Teknik pengambilan gambar yang dilakukan oleh penulis adalah dokumentasi, penulis hanya mengamati objek dan mendokumentasikan aktifitasnya, hal ini dilakukan karena penulis ingin mengetahui bagaimana aktifitas kebiasaan dari anak autis.

Observasi yang pertama dilakukan pada 14 Maret 2019 dengan Azka, Azka adalah pengidap autis tipe Rett Syndrome, pada observasi ini penulis bekerja sama dengan tempat penelitian untuk meminta waktu pada saat Azka menjalani terapi, selama terapi penulis melakukan observasi dan melakukan pengambilan gambar.

Observasi kedua dilaksanakan pada tanggal 19 Maret 2019 dengan Rizah, Rizah merupakan pengidap autis tipe Aspeger Syndrome. Sama seperti observasi dengan Azka, penulis juga bekerja sama dengan tempat penelitian untuk melakukan observasi pada saat terapi.

Observasi ketiga dilaksanakan pada tanggal 19 April 2019 yang dilaksanakan di pasar merdeka, observasi ini dilakukan untuk mengambil gambar lingkungan sosial yang padat, pada rencana awal, penulis tidak merencanakan melakukan observasi ini, namun disaat proses editing, penulis merasa perlu memasukan Footage sosial yang padat, maka dari itu penulis memutuskan menambahkan observasi ini.

\subsection{Duik Tool}

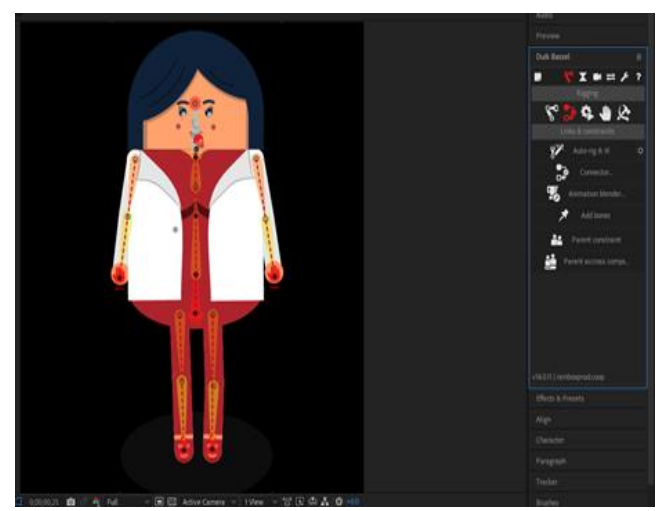

Gambar 7. Karakter Dengan Duik Tool

Pembuatan animasi difokuskan dengan menggunakan teknik Rigged dengan menggunakan Duik Tool. Rigged adalah teknik menggerakan suatu asset dengan pemberian struktur tulang, dalam penelitian ini penulis menggunakan teknik rigged untuk membuat animasi karakter manusia pada animasi. Ada 4 langkah dalam pembuatan rigged menggunakan duik tool, yang pertama adalah pembuatan karakter, karakter dibuat sedemikian rupa dengan bentuk manusia, penulis melakukan pembuatan karakter menggunakan Adobe Illustrator, setelah karakter ada, baru dilakukan proses pembuatan tulang, proses pembuatan tulang ini berguna untk mendakan, bagian sikusiku yang nantinya ada pada karakter, biasanya pembuatan tulang pada bagian siku tangan dan lutut kaki, setelah pembuatan bones structure, pembuatan bones structure ini dapat di buat otomatis oleh duik tool. Saat structure terbentuk lalu di paskan dengan bones yang sudah dibuat, lalu Generate Auto-Rig \& IK. Setelah itu penulis melakukan proses pergerakan animasi pada karakter.

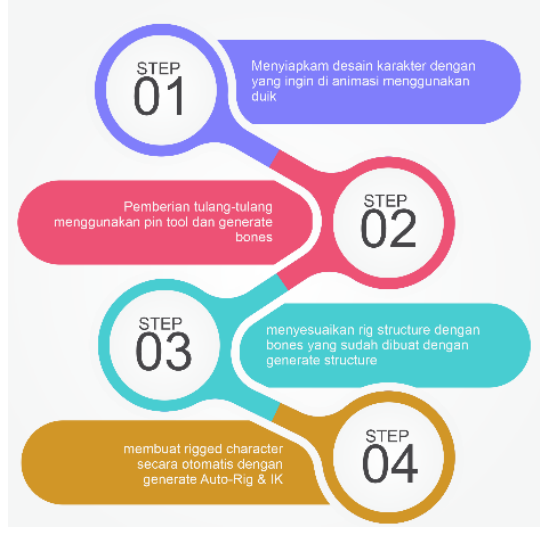




\section{Gambar 8. Skema Duik Tool}

\subsection{Animasi}

Animasi yang terdapat dalam video ini sebagaian besar menggunakan teknik rigged, namun selain menggunakan teknik rigged penulis juga menggunakan teknik motion graphic. Penggunaan teknik Motion Graphic diperlukan sebagai pergerakan objek, background, dan asetaset lainnya selain dari asset karakter.

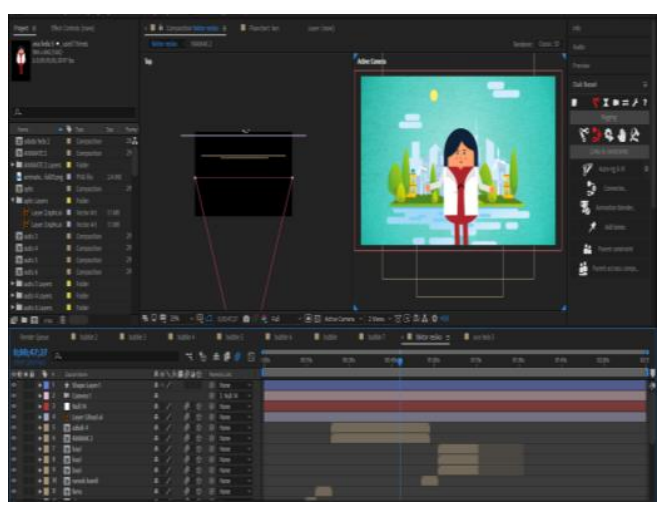

Gambar 9. Proses Membuat Animasi

\subsection{Editing}

Proses editing dilakukan menggunakan Adobe Premiere Pro CC 2018. Penulis menggakan software ini untuk melakukan composing atau penggabungan potongan-potongan video, menggabungkan video dan animasi, pemberian SFX (Sound Effect) atau efek suara, pemberian background music. Merekam narasi dan voice over atau perekaman suara pada karakter Hela juga penulis lakukan melalui software ini.

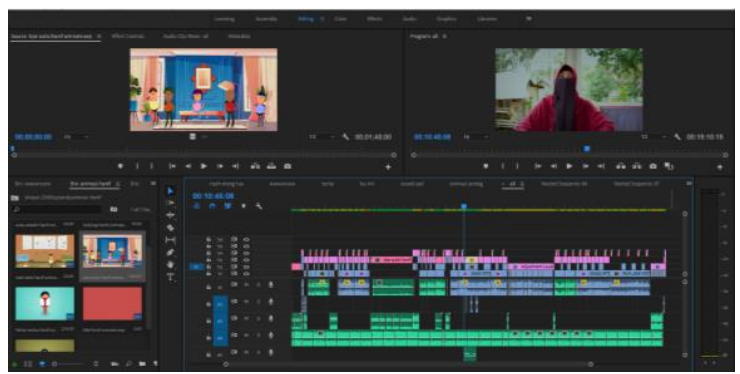

Gambar 10. Proses Editing

\subsection{Output Video}

Setelah video ini di render dan di export maka dihasilkan video dengan Detail informasi sebagai berikut:
a. Judul
: Autism \& Society
b. Durasi
c. Resolusi
:19 menit 11 detik.
d. Total bitrate
:1920 x 1080
e. Frame rate
:9942kbbps
: 23.98 frames/second
f. Audio bitrate :317kbps
g. Channels :2(Stereo)
h. Audio sample rate: $48.000 \mathrm{k} \mathrm{Hz}$

\subsection{Publikasi}

Video ini di unggah ke youtube pada tanggal 14 mei 2019 di akun Infinedd Cinema dan penulis mempublikasikan video ini secara luas pada 19 Mei 2019. Penulis ingin video ini dapat dilihat oleh seluruh lapisan masyarakat, mengingat kasus autis ada di setiap lapisan masyarkat. Setelah di publikasi akan dilakukan promosi, penulis melakukan promosi di media instragram dengan menggunakan fitur Promote pada Instagram, penulis akan membuat video iklan berduasi 1 menit di instagram yang akan didaftarkan pada Promote, promote adalah salah satu fitur yang terdapat dalam Instagram yang berguna untuk menyebar luaskan iklan. Media sosial merupakan jaringan teknologi yang digunakan untuk menciptakan berita melalui pengguna internet dan mengkomunikasikan serta mendiseminasikan informasi, sedangkan pemasaran media sosial merupakan suatu jenis model pemasaran internet untuk mencapai tujuan pemasaran dengan berpartisipasi dalam lingkup jaringan media sosial. pada perkembangannya media sosial bukan hanya digunakan untuk kebutuhan pribadi saja, kini media sosial diperluas kegunaannya untuk aspekaspek yang lain, salah satunya adalah aspek bisnis khususnya promosi. Penulis merencanakan mendaftarkan Promote dengan durasi 1 minggu, dengan lokasi local di samarinda dan dengan kisaran umur mulai dari 13 tahun hingga 65 tahun, berjenis kelamin laki-laki dan perempuan. Dana yang dikelaurkan penulis adalah Rp $50.000,00$ perhari dan penulis memakai promote selama 6 hari yang berearti total biaya yang dikeluarkan penulis sebesar Rp 300.000,00.

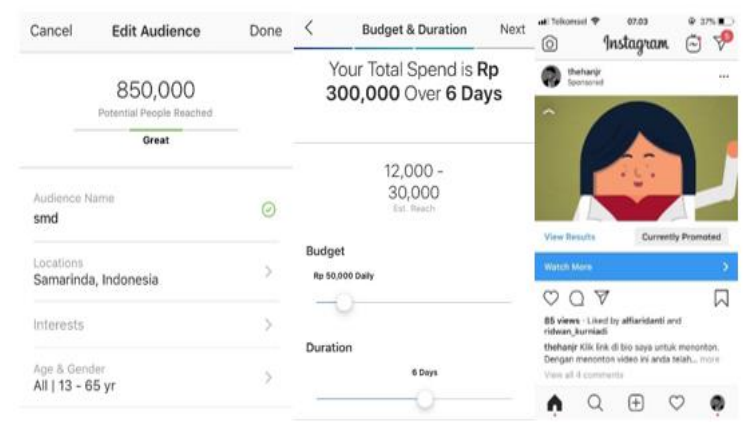

Gambar 11. Instagram Promote 
Dapat dilihat jumlah view Instagram setelah beberapa jam menjadi 85 view, dan setelah 24 jam meningkat menjadi 926 View, peningkatan jumlah view ini cukup dan jika dilihat dari promotion insight dapat disimpulkan bahwa dari 4.357 user yang diraih iklan, impresionnya adalah 5,434 atau $76 \%$ dari promotion, impression adalah total orang yang melihat iklan berulang kali. Dan audience yang di raih berdasarkan jenis kelamin adalah $30 \%$ perempuan dan $70 \%$ laki-laki, age range yang diraih paling banyak dengan age range 18-24 tahun yaitu sebesar 38\%, disusul oleh 13-17 tahun yaitu 22\%, sedangkan 25-34 tahun 18\%, sisanya ada $13-44,45-54,65+$ yang dibawah $12 \%$ dan paling sedikit ada di umur 55-64 yaitu 2\%.

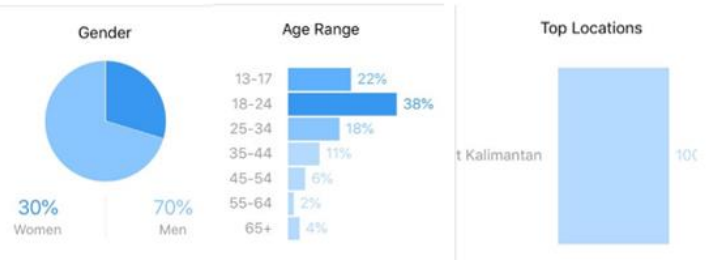

Gambar 12. Audience Pada Instagram Promote

Namun perkembangan iklan di fitur promote Instagram rupanya tidak berbanding baik dengan jumlah viewer youtube. Nyatanya perkembangan viewer di youtube sangat lambat, dalam 24 jam viewer youtube hanya bertambah 46 views.

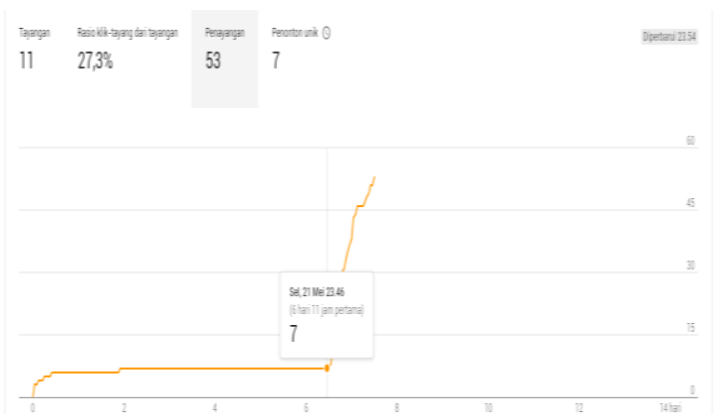

Gambar 13. Jumlah Views Youtube Sebelum Melakukan Promosi

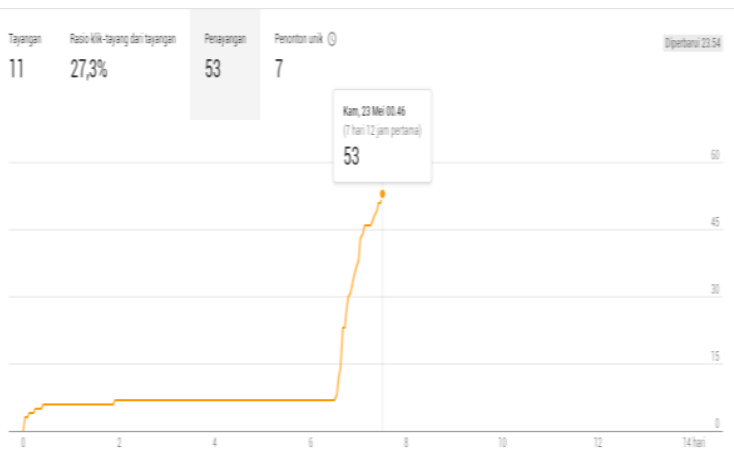

Gambar 14. Jumlah Views Youtube Setelah Melakukan Promosi 24 Jam

Dari total jumlah viewer, jenis asal trafficnya adalah sebagai berikut.

Jenis asal traffic
Waktu menonton · Sejak dipublikasikan
Eksternal
Penelusuran YouTube
Halaman channel
Fitur YouTube lainnya
Notifikasi
LIHAT LAINNYA

Gambar 15. Jenis Asal Traffic Youtube

Sebanyak 71,8\% viewer berasal dari external, yang artinya sebagian besar viewer menonton video ini melalui link yang disebarkan melalui promo Instagram.

\section{Kesimpulan dan Saran}

Berdasarkan hasil penelitian tersebut maka didapatkan kesimpulan bahwa penambahan elemen animasi dalam video sangat mungkin dilakukan, dan penambahan animasi di dalam video dapat membantu menambahkan informasi yang tidak dapat dicapai dengan video. Melakukan promosi video menggunakan fitur promote Instagram dapat meningkatkan jumlah traffic pada video Youtube, namun kurang menarik minat user Instagram untuk membuka iklan yang mengarah ke link youtube. 
Berdasarkan hasil evaluasi dari penelitian ini maka terdapat adanya beberapa kekurangan yang perlu diperbaiki di penelitian selanjutnya. Penulis harus mengatur jadwal shooting dengan baik agar tidak terjadi keterlambatan produksi. Wawancara harus direncanakan dengan lebih baik lagi agar tidak saat melakukan wawancara narasumber dapat berbicara dengan jelas dan tidak terbata-bata. Dalam memproduksi sebuah video tentunya dibutuhkan sebuah tim, penulis menyarankan pada penelitian selanjutnya sebaiknya dibentuk tim untuk mengerjakan tiap elemen yang terdapat dalam produk akhir sesuai dengan keahlian masing-masing, terutama untuk menambahkan elemen-elemen pendukung animasi seperti efek suara, latar suara, desainer, dan lainnya, agar hasil menjadi lebih maksimal dan dapat dinikmati lebih baik oleh penonton. melihat narasumber berbicara. Lebih mematangkan perencaan iklan di Instagram promote, untuk menguji seberapa efektif menggunakan iklan di Instagram, penulis halus merencanakan lebih detail lagi tentang pemasangan iklan di Instagram promote, membuat sasaran kusus pada audience di Instagram promote dapat membantu proses sosialisasi iklan lebih tepat sasaran dan dapat memperbesar peluang audience yang menerima iklan pergi ke link yang sudah disediakan oleh Instagram ke video utama di youtube.

\section{Daftar Pustaka:}

[1] G. Nithin and R. S. Bhooshan, "ARTARArtistic Augmented Reality," Procedia Technol., vol. 24, pp. 1468-1474, 2016.

[2] Y. Sasaki and A. R. Work, "Efficient Virtual View Rendering by Merging Pre-rendered RGB-D Data from Multiple Cameras," pp. 03, 2018.

[3] E. Budiman, N. Pusnitasari, M. Wati, Haeruddin, J. A. Widians, and A. Tejawati, "Mobile learning media for computer science course," Int. Electron. Symp. Knowl. Creat. Intell. Comput. IES-KCIC 2018 - Proc., pp.
262-267, 2019.

[4] M. B. Firdaus, "Pengembangan Alat Ukur Keterbukaan Informasi Publik pada Situs Web Pemerintah Studi Kasus Kabupaten Kutai Kartanegara," J. Ilm. Ilmu Komput., vol. 3, no. 1, pp. 7-13, 2017.

[5] H. Mayilyan, "Implementation of Augmented Reality Globe in Teaching-Learning Environment," Proc. - 2nd Int. Conf. Multimed. Inf. Process. Retrieval, MIPR 2019, pp. 389-390, 2019.

[6] L. Chen, W. Huang, A. Sui, D. Chen, and C. Sun, "The online education platform using Proxmox and noVNC technology based on Laravel framework," Proc. - 16th IEEE/ACIS Int. Conf. Comput. Inf. Sci. ICIS 2017, pp. 487-491, 2017.

[7] C. Hutton and E. Suma, "A realistic walking model for enhancing redirection in virtual reality," Proc. - IEEE Virtual Real., vol. 2016July, pp. 183-184, 2016.

[8] E. Ardhianto, "Augmented Reality Objek 3 Dimensi dengan Perangkat Artoolkit dan Blender," Din. Teknol. ..., vol. 17, no. 2, pp. 107-117, 2012.

[9] Y. Yang, B. C. Lovell, and F. Dadgostar, "Content-Based Video Retrieval (CBVR) system for CCTV surveillance videos," DICTA 2009 - Digit. Image Comput. Tech. Appl., no. December 2007, pp. 183-187, 2009.

[10] Imtihan, K., \& Basri, M. H. (2019). SISTEM INFORMASI PEMBUATAN MANIFEST MUATAN KAPAL BERBASIS DEKSTOP DAN ANDROID. Jurnal Manajemen Informatika dan Sistem Informasi, 2(2), 69-76.

[11]Khairul Imtihan. "Perencanaan Strategi Sistem Informasi Pendidikan Pada Sekolah Tinggi Manajemen Informatika dan Komputer (STMIK) Lombok." Bianglala Informatika 3, no. 2 (2015).

[12] M. V. Fedewa, B. S. Nickerson, and M. R. Esco, "Associations of body adiposity index, waist circumference, and body mass index in young adults," Clin. Nutr., pp. 6-11, 2018.

[13] M. Jago, Adobe Premiere Pro CC Classroom in a Book 2019 Release. San Jose, California, USA: Adobe Press, 2019. 